\author{
Emilie Barriau \\ Holger Frey \\ Anton Kiry \\ Manfred Stamm \\ Franziska Gröhn
}

\section{Negatively charged hyperbranched polyether-based polyelectrolytes}

Received: 25 April 2006

Accepted: 16 May 2006

Published online: 21 June 2006

(C) Springer-Verlag 2006

\section{F. Gröhn}

Max Planck Institut für

Polymerforschung,

Ackermannweg 10,

55128 Mainz, Germany

\begin{abstract}
The preparation of carboxylated hyperbranched polyglycerols of narrow polydispersity was achieved by modification (78-90\%) of the hydroxyl end groups via Michael addition of acrylonitrile, followed by hydrolysis. High conversion could only be achieved for low molecular weight starting materials (520 and $1,030 \mathrm{~g} \mathrm{~mol}^{-1}$ ). The solution properties of the resulting materials were investigated by dynamic light scattering (DLS), showing the formation of large aggregates with size depending
\end{abstract}

on the $\mathrm{pH}$ value. After deposition on a negatively charged mica surface, the structures observed by atomic force microscope (AFM) show the coexistence of aggregates and single macromolecules.

Most interesting, in the case of the lower molecular weight sample (PG $520 \mathrm{~g} \mathrm{~mol}^{-1}$ ), extended and ordered terrace structures were formed, which are unprecedented for hyperbranched polymers and are of interest for surface modification in general.

Keywords Hyperbranched polyelectrolyte - Michael addition . Ordered structures

Dresden e.V. (IPF)

Hohe Strasse 6 ,

01069 Dresden, Germany

\section{Introduction}

Polyelectrolytes play an important role in numerous areas, e.g., to control the stability and rheology of complex fluids, for flocculation, and biomineralization processes. Polyelectrolyte-based materials are also widely applied in coatings, thickeners, dispersants, detergent-additives, and ion-exchange resins. Thus, the development of novel polyelectrolytes with unusual topology has become a topic of broad interest for both Colloid and Polymer Science, as these polymers are likely to exhibit peculiar properties in aqueous solution, that can strongly influence the fluid characteristics of aqueous suspensions and slurries, permit the introduction of surface charges on neutral particles via adsorption and may also lead to strong interaction with ions or colloidal aggregates of opposite charge.
In several recent works, highly branched polyelectrolyte structures have been introduced that are mostly based on perfectly branched dendrimer scaffolds [1-4]. Müller et al. have described a versatile strategy for hyperbranched polyelectrolytes based on the self-condensing vinyl (co) polymerization of protected acrylate monomers and subsequent hydrolysis [5].

A long-known example of a highly branched polyelectrolyte is poly(ethyleneimine), PEI. For PEI, pH-variation leads to strong variation of the properties in aqueous solution, as the charge-density on the amine-groups is $\mathrm{pH}$ dependent [6]. Furthermore, a number of theoretical works has dealt with charged, branched polyelectrolyte structures [7-9]. Among the hyperbranched structures, polyglycerol prepared by slow addition of glycidol to a partially deprotonated polyol core [10] represents a particularly interesting 
material, as it is biocompatible [11] and can be prepared with controlled molecular weight and low polydispersity. In an elegant recent work, Schwab and Mecking reported the preparation of cationically charged polyglycerol-based polyelectrolytes, based on the attachment of pyridinium and imidazolium functionalities to polyglycerol [12]. Haag et al. have recently introduced a synthesis for hyperbranched polyglycerol-based carboxylates based on conversion with sodium chloro-acetate, which, however, only led to a limited conversion of $26 \%$ of the hydroxyl end groups [12].

For the synthesis of polyamine-dendrimers, poly(propylene imines) [13-15], the Michael addition to the amino end groups plays a key role to obtain the polynitrile intermediates. In this case, even in high dendrimer generations, the dendrimer periphery can be fully modified. A subsequent hydrolysis step can also be employed to generate carboxylic acid end groups, thus, leading to dendritic polyelectrolytes. This method has also been successfully employed for the preparation of amphiphilic linear-dendritic block copolymers by Meijer et al. [16].

In this paper, a convenient pathway for the modification of the hydroxyl end groups of hyperbranched polyglycerol into carboxylic acid groups, and thereby, the formation of a hyperbranched, anionically charged polyelectrolyte is presented. The solution properties of these new hyperbranched polyelectrolytes will be discussed. Furthermore, the materials have been deposited on mica to generate ultrathin multilayers that have been investigated by atomic force microscope (AFM).

\section{Experimental part}

\section{Materials}

Acetone, methanol, tert-butoxide, sodium hydroxide, sodium sulfite, and $30 \%$ weight $\mathrm{H}_{2} \mathrm{O}_{2}$ solution were used as received from Fluka. Acrylonitrile and dimethylformamide (DMF) were obtained from Fluka and distilled before use.

\section{Syntheses}

\section{Preparation of 3-(O-Polyglycerol)propanenitrile}

Hyperbranched polyglycerol $(500 \mathrm{mmol})$ was placed in a reactor and dissolved in 15-ml absolute DMF under argon atmosphere. Potassium tert-butoxide was added to the polymer solution to achieve $10 \%$ deprotonation of the hydroxyl groups. The reaction mixture was stirred and heated up to $80{ }^{\circ} \mathrm{C}$ for $4 \mathrm{~h}$ and then cooled down to $0{ }^{\circ} \mathrm{C}$. Distilled acrylonitrile $(61 \mathrm{mmol})$ was slowly added via a syringe to the reactor and the temperature was kept at $0{ }^{\circ} \mathrm{C}$. After $4 \mathrm{~h}$, the reactor was heated up to $5{ }^{\circ} \mathrm{C}$, the solution became slightly red. The reaction mixture was kept at $5{ }^{\circ} \mathrm{C}$ for another $20 \mathrm{~h}$, and finally, for $48 \mathrm{~h}$ at room temperature. Then $1 \mathrm{~g}$ of a cationic exchange resin was added to the reactor and that was stirred for $24 \mathrm{~h}$. After filtration, DMF and the remaining acrylonitrile were removed by distillation. The modified polyglycerol was first dissolved in acetone and then precipitated in methanol, obtaining a brownish product. Both fractions were analyzed. The acetone fraction is a solid and the methanol soluble fraction is a highly viscous oil. The 3-( $O$-polyglycerol)propanenitrile was dried in vacuum at $50{ }^{\circ} \mathrm{C}$.

Proton nuclear magnetic resonance $\left({ }^{1} \mathrm{H}\right.$ NMR $)(300 \mathrm{MHz}$, DMSO- $\mathrm{d}_{6}$ or $\left(\mathrm{CD}_{3}\right)_{2} \mathrm{CO}, \delta$ in ppm): $3.9-3.3\left(\mathrm{CH}_{3}-\mathrm{CH}_{2}-\mathrm{C}\right.$ $\left.\left(\mathrm{CH}_{2}-\mathrm{O}\right)_{3}-\left[\mathrm{PG}-\mathrm{CH}_{2}-\mathrm{CH}_{2}-\mathrm{CN}\right]_{x}, \mathrm{~m}\right) ; 2.7\left(\mathrm{CH}_{3}-\mathrm{CH}_{2}-\right.$ $\left.\mathrm{C}\left(\mathrm{CH}_{2}-\mathrm{O}\right)_{3}-\left[\mathrm{PG}-\mathrm{CH}_{2}-\mathrm{CH}_{2}-\mathrm{CN}\right]_{x}, \mathrm{~s}\right) ; 1.3 \quad\left(\mathrm{CH}_{3}-\mathrm{CH}_{2}-\mathrm{C}\right.$ $\left.\left(\mathrm{CH}_{2}-\mathrm{O}\right)_{3}-\left[\mathrm{PG}-\mathrm{CH}_{2}-\mathrm{CH}_{2}-\mathrm{CN}\right]_{\mathfrak{r}}, \mathrm{m}\right) ; 0.87\left(\mathrm{CH}_{3}-\mathrm{CH}_{2} \mathrm{C}\left(\mathrm{CH}_{2}\right.\right.$ $\left.\mathrm{O})_{3}-\left[\mathrm{PG}-\mathrm{CH}_{2}-\mathrm{CH}_{2}-\mathrm{CN}\right]_{\mathfrak{r}}, \mathrm{m}\right)$.

\section{Preparation of 3-(O-polyglycerol)propanoate}

3-(O-polyglycerol)propanenitrile ( $2 \mathrm{~g})$ was placed in $120-\mathrm{ml} 3-\mathrm{N}$ sodium hydroxide solution. A $30 \%$ weight $\mathrm{H}_{2} \mathrm{O}_{2}$ solution $(10 \mathrm{ml})$ was carefully added, and the mixture was stirred for $1 \mathrm{~h}$ at $70{ }^{\circ} \mathrm{C}$, then for 1 day at $80{ }^{\circ} \mathrm{C}$, and finally cooled down to room temperature for 2 days. A 2-M sodium sulfite solution was added and the reaction mixture was dialyzed for 2 days in water. The product is a slightly yellow solid.

Modified procedure: the product was precipitated in ethanol, and the reaction was repeated, until the conversion of the nitrile to carboxylate was satisfactory.

${ }^{1} \mathrm{H}$ NMR (300 MHz, $\mathrm{D}_{2} \mathrm{O}, \quad \delta$ in ppm): 3.9-3.3 $\left(\mathrm{CH}_{3}-\mathrm{CH}_{2}-\mathrm{C}\left(\mathrm{CH}_{2}-\mathrm{O}\right)_{3}-\left[P G-\mathrm{CH}_{2}-\mathrm{CH}_{2}-\mathrm{COONa}\right]_{x} \mathrm{~m}\right)$; $2.4\left(\mathrm{CH}_{3}-\mathrm{CH}_{2}-\mathrm{C}\left(\mathrm{CH}_{2}-\mathrm{O}\right)_{3}-\left[\mathrm{PG}-\mathrm{CH}_{2}-\mathrm{CH}_{2}-\mathrm{COONa}\right]_{x}, \mathrm{~s}\right)$; $1.3\left(\mathrm{CH}_{3}-\mathrm{CH}_{2}-\mathrm{C}\left(\mathrm{CH}_{2}-\mathrm{O}\right)_{3}-\left[\mathrm{PG}-\mathrm{CH}_{2}-\mathrm{CH}_{2}-\mathrm{COONa}\right]_{x}\right.$, $\mathrm{m}) ; \quad 0.87 \quad\left(\mathrm{CH}_{3}-\mathrm{CH}_{2}-\mathrm{C}\left(\mathrm{CH}_{2}-\mathrm{O}\right)_{3}-\left[\mathrm{PG}-\mathrm{CH}_{2}-\mathrm{CH}_{2}-\right.\right.$ $\left.\mathrm{COONa}]_{x}, \mathrm{~m}\right)$.

${ }^{13} \mathrm{C}$ NMR (75.4 MHz, $\mathrm{D}_{2} \mathrm{O}, \quad \delta$ in ppm): 180 $\left(\mathrm{CH}_{3}-\mathrm{CH}_{2}-\mathrm{C}\left(\mathrm{CH}_{2}-\mathrm{O}\right)_{3}-\left[\mathrm{PG}-\mathrm{CH}_{2}-\mathrm{CH}_{2}-\mathrm{COONa}\right]_{x}\right) ; 77-$ $66\left(\mathrm{CH}_{3}-\mathrm{CH}_{2}-\mathrm{C}\left(\mathrm{CH}_{2}-\mathrm{O}\right)_{3}-\left[\mathrm{PG}-\mathrm{CH}_{2}-\mathrm{CH}_{2}-\mathrm{COONa}\right]_{x}\right)$; $61 \quad\left(\mathrm{CH}_{3}-\mathrm{CH}_{2}-\mathrm{C}\left(\mathrm{CH}_{2}-\mathrm{O}\right)_{3}-\left[\mathrm{PG}-\mathrm{CH}_{2}-\mathrm{CH}_{2}-\mathrm{COONa}\right]_{x}\right)$; $43\left(\mathrm{CH}_{3}-\mathrm{CH}_{2}-\mathrm{C}\left(\mathrm{CH}_{2}-\mathrm{O}\right)_{3}-\left[\mathrm{PG}-\mathrm{CH}_{2}-\mathrm{CH}_{2}-\mathrm{COONa}\right]_{x}\right)$; $37\left(\mathrm{CH}_{3}-\mathrm{CH}_{2}-\mathrm{C}\left(\mathrm{CH}_{2}-\mathrm{O}\right)_{3}-\left[\mathrm{PG}-\mathrm{CH}_{2}-\mathrm{CH}_{2}-\mathrm{COONa}\right]_{x}\right)$; $22\left(\mathrm{CH}_{3}-\mathrm{CH}_{2}-\mathrm{C}\left(\mathrm{CH}_{2}-\mathrm{O}\right)_{3}-\left[\mathrm{PG}-\mathrm{CH}_{2}-\mathrm{CH}_{2}-\mathrm{COONa}\right]_{x}\right)$; $7.5\left(\mathrm{CH}_{3}-\mathrm{CH}_{2}-\mathrm{C}\left(\mathrm{CH}_{2}-\mathrm{O}\right)_{3}-\left[\mathrm{PG}-\mathrm{CH}_{2}-\mathrm{CH}_{2}-\mathrm{COONa}\right]_{x}\right)$.

\section{Methods}

AFM measurements were carried out in the dry state with a multimode AFM instrument (Digital Instruments, Santa Barbara) operated with amplitude feedback in "light" tapping mode (amplitude set point in the range of 0.99 0.95 ). Silicon tips with a radius of 10-20 nm, spring constant of $0.3 \mathrm{~N} \mathrm{~m}^{-1}$, and resonance frequency of 250 $300 \mathrm{kHz}$ were used after the calibration with gold nanoparticles (diameter: $5.22 \mathrm{~nm}$, Pelco AFM Gold Standard Kit.) to evaluate the tip radius. All measurements 
were done at ambient conditions (temperature: $21 \pm 2{ }^{\circ} \mathrm{C}$; relative humidity: $50-70 \%$ ).

Light scattering measurements were performed with a setup for combined static and dynamic light scattering consisting of an ALV/SP-86 goniometer and an ALV-5000/E multitau correlator. A He-Ne laser operating at a wavelength of $532 \mathrm{~nm}$ with a maximum output power of $375 \mathrm{~mW}$ was used as light source. Solutions were cleared by using a Millipore $0.22-\mu \mathrm{m}$ pore size Teflon filter into $1-\mathrm{cm}$ diameter dust-free quartz cells.
Size exclusion chromatography (SEC) measurements were performed with a Shodex differential refractometer RI 71 in DMF with $\operatorname{LiBr}\left(75^{\circ} \mathrm{C}\right.$, column PSS GRAL e4/3/2) or chloroform $\left(30^{\circ} \mathrm{C}\right.$, columns PSS SDV e $4 / 3 / 2$ and SDV e9/5/4) as eluent by injection of $150 \mu \mathrm{l}$ of the polymer solution. Polystyrene standards were used for calibration.

NMR spectra were recorded at concentrations of $100 \mathrm{~g}^{-1}$ on Bruker ARX 300 spectrometer operating at $300 \mathrm{MHz}$ $\left({ }^{1} \mathrm{H}\right.$ NMR $)$ and $75.4 \mathrm{MHz}\left({ }^{13} \mathrm{C}\right.$ NMR $)$.<smiles>CCC(COCC(O)COCC(COCC(COCC(O)CO)OCC(O)CO)OCC(O)CO)(COCC(CO)OCC(COCC(O)COCC(CO)OCC(O)CO)OCC(O)CO)COCC(COCC(O)COCC(O)CO)OCC(COCC(O)CO)OCC(O)CO</smiles>

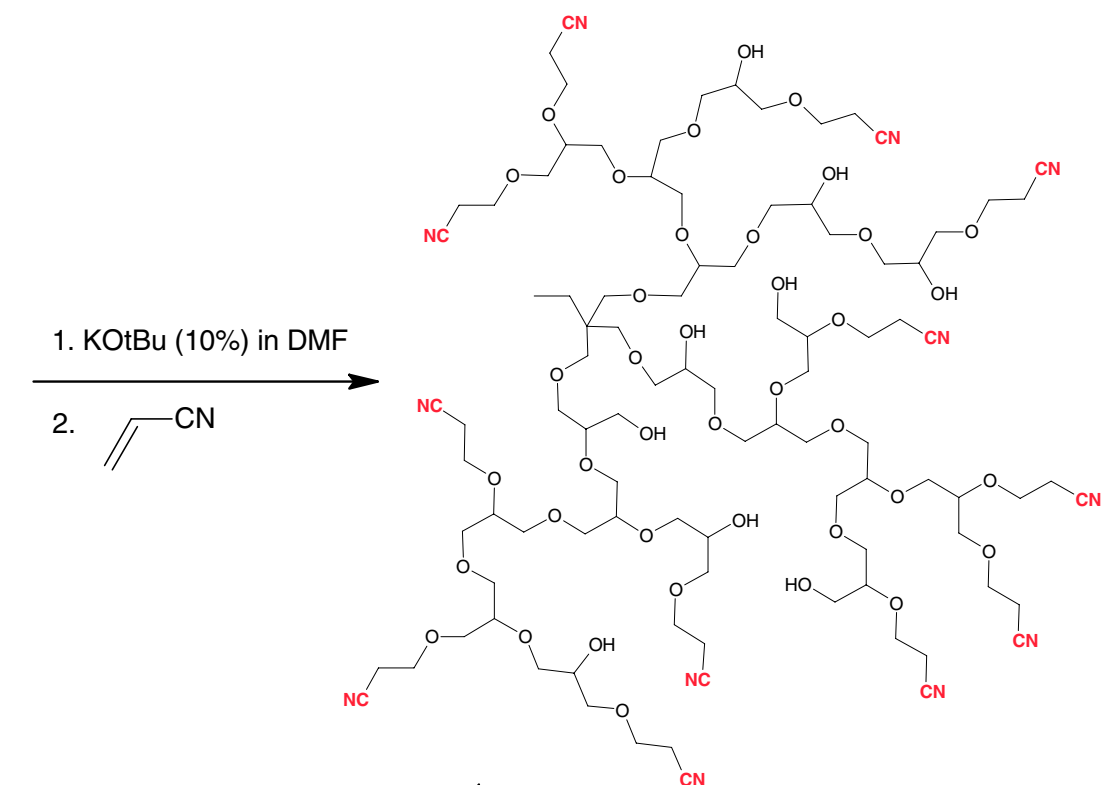

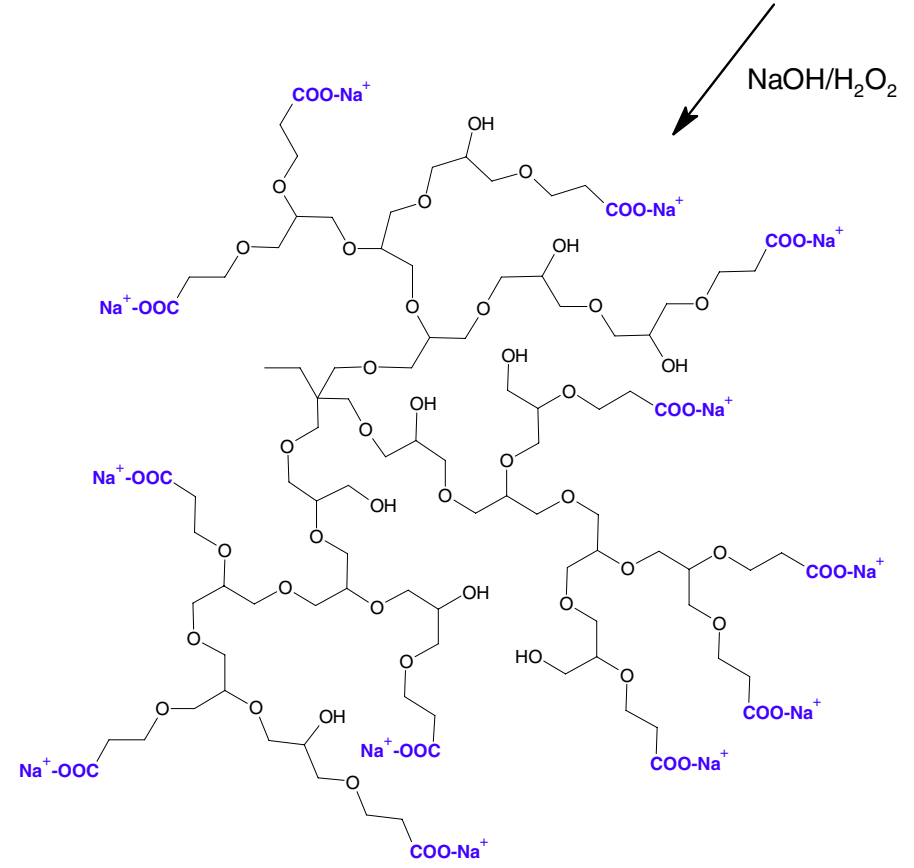

Scheme 1 Synthesis of carboxylated hyperbranched polyglycerol via Michael addition, followed by hydrolysis of the nitrile termini 
Fig. $1{ }^{1} \mathrm{H}$ NMR spectrum

of a $\mathrm{PG}_{15}$ in methanol-d $\mathrm{d}_{4}$;

b $\mathrm{PG}_{15} \mathrm{CN}_{13}$ in acetone- $\mathrm{d}_{6}$;

c $\mathrm{PG}_{15}\left(\mathrm{COO}^{-} \mathrm{Na}^{+}\right)_{13}$ in $\mathrm{D}_{2} \mathrm{O}$ (sample 2 in Table 1)
A) Methanol-d4

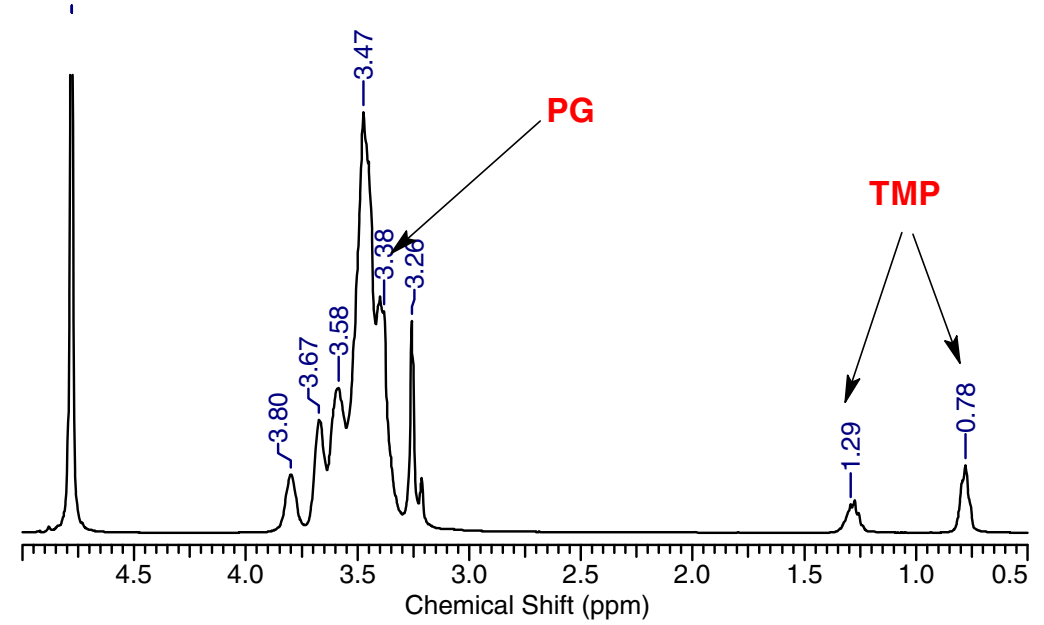

B)

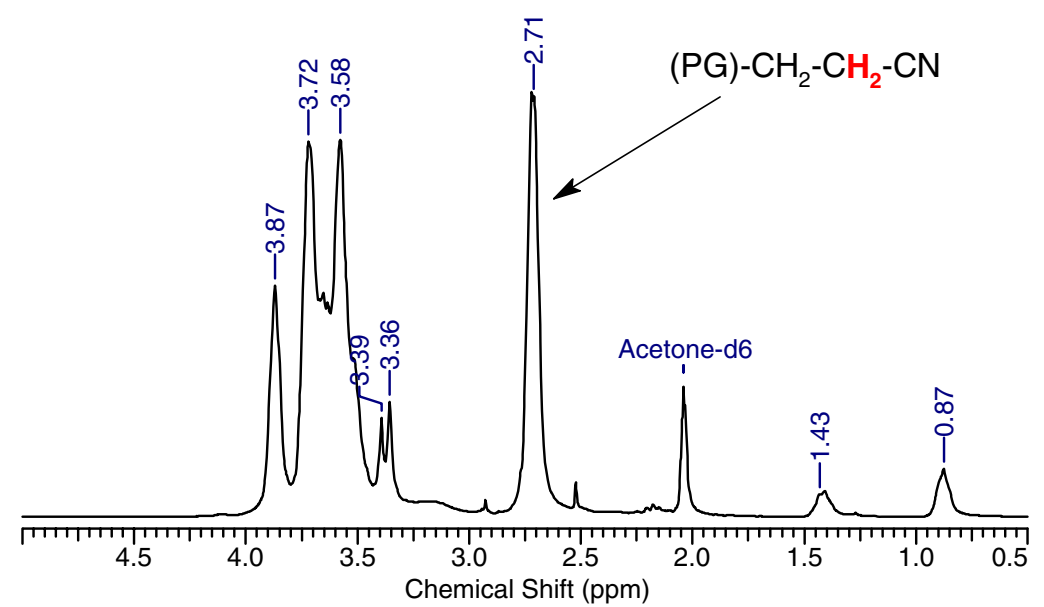

C)

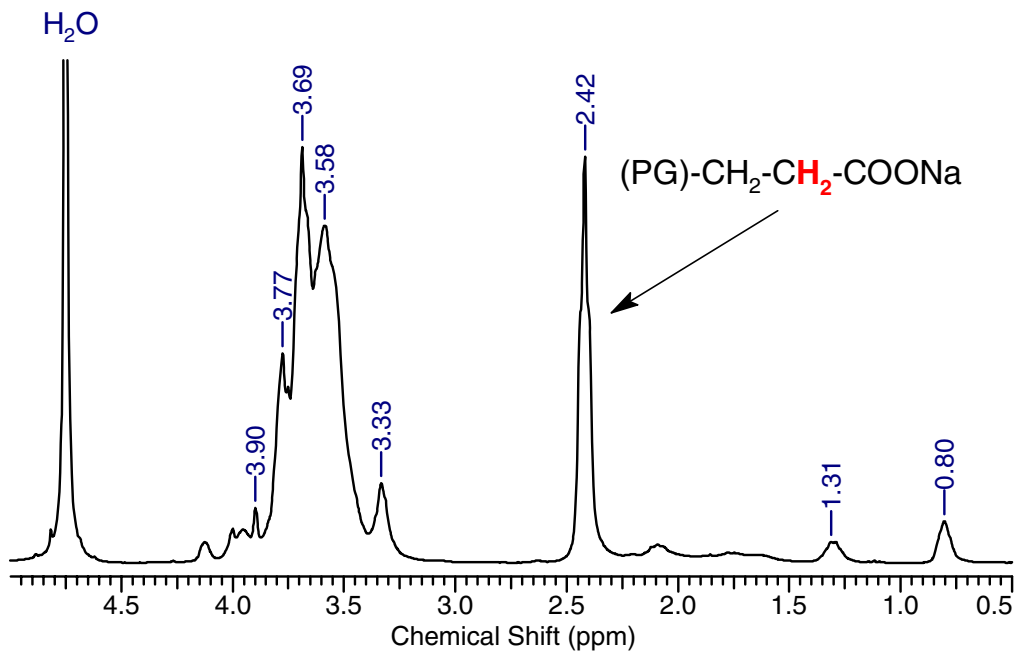




\section{Results and discussion}

Synthesis

Hyperbranched polyglycerol was prepared by slow addition of glycidol to a trimethylolpropane core, leading to low polydispersities in the range of $M_{w} / M_{n}=1.3-1.7$ and controlled molecular weight, as described previously [10]. This polyether-polyol can conveniently be modified at the hydroxyl end groups. Reactions employed for the functionalization should fulfill the following criteria: (1) high degree of conversion, (2) the compounds have to remain soluble in the medium, and (3) the work-up procedure has to be convenient. Modification into carboxylic groups was achieved via Michael addition reaction followed by hydrolysis, as shown in Scheme 1.

In the first step, the hydroxyl groups are converted into nitrile groups. Obviously, the products obtained after this step are hydrophobic. Hyperbranched polyglycerol was dissolved in DMF and partially deprotonated $(10 \% \mathrm{~mol}$ of the hydroxyl groups). During addition of acrylonitrile, the temperature had to be kept under $0{ }^{\circ} \mathrm{C}$ to control the reaction. The materials were precipitated twice from acetone solution into methanol. The products obtained were viscous and brownish. DSC measurements showed that the glass transition temperature of the polymer was not affected by the functionalization; it remained at around $-20^{\circ} \mathrm{C}$. In the second step, the nitrile groups were hydrolyzed with hydrogen peroxide in the presence of sodium hydroxide (Scheme 1). After this procedure the materials became soluble in aqueous solution. The carboxylated products were then precipitated in diethyl ether. The carboxylated hyperbranched polyglycerols are obtained as solid, slightly yellow materials. The products were additionally purified by dialysis in water.

Figure 1a shows the ${ }^{1} \mathrm{H}$ NMR spectrum of hyperbranched polyglycerol. The signals between 3.3 and
$3.8 \mathrm{ppm}$ are due to the polyether protons. Resonances at $0.8 \mathrm{ppm}$ are due to the methyl group and signals at $1.3 \mathrm{ppm}$ stem from the methylene group of the inititor-core TMP. After the Michael addition reaction, the two protons next to the nitrile group result in a new signal at $2.7 \mathrm{ppm}$ (Fig. 1b). This signal is shifted to $2.4 \mathrm{ppm}$ after hydrolysis (Fig. 1c). Elemental analysis has also been performed to trace the nitrogen content before and after hydrolysis to monitor the extent of hydrolysis.

The ${ }^{13} \mathrm{C}$ NMR spectrum of the carboxylated hyperbranched polyglycerol (Fig. 2) also shows the expected signals at $180 \mathrm{ppm}$ for the carboxylic acid groups and at $37 \mathrm{ppm}$ for the carbon next to this group, confirming hydrolysis.

A series of hyperbranched polyglycerols with different molecular weights has been transformed to the respective polyelectrolytes (Table 1). For the samples 1 and 2, the degree of modification achieved was between 80 and $90 \%$ and around $60 \%$ for the samples 3 and 4 (higher molecular weights). As expected, the degree of conversion decreased with increasing molecular weight, i.e., with increasing endgroup functionality. The reaction of hydroxyl groups located in the proximity of the core of the hyperbranched architecture is most likely more difficult than transformation of the ones present at the periphery. This is analogous to the difficulties encountered when functionalizing the interior of dendrimer structures. It is obvious that all samples possess some remaining hydroxyl groups. This can be interesting in the case of application, e.g., for guest encapsulation [17]. In this case, such groups may act, e.g., as interaction site for guest molecules.

The hyperbranched polynitriles are also interesting for further conversion into other functional groups, such as amine groups after reduction, in analogy to the preparation of polypropylenimine (PPI) dendrimers [13-15].
Fig. $2{ }^{13} \mathrm{C}$ NMR spectrum of $\mathrm{PG}_{15}\left(\mathrm{COO}^{-} \mathrm{Na}^{+}\right)_{13}$ in $\mathrm{D}_{2} \mathrm{O}$ (sample 2)

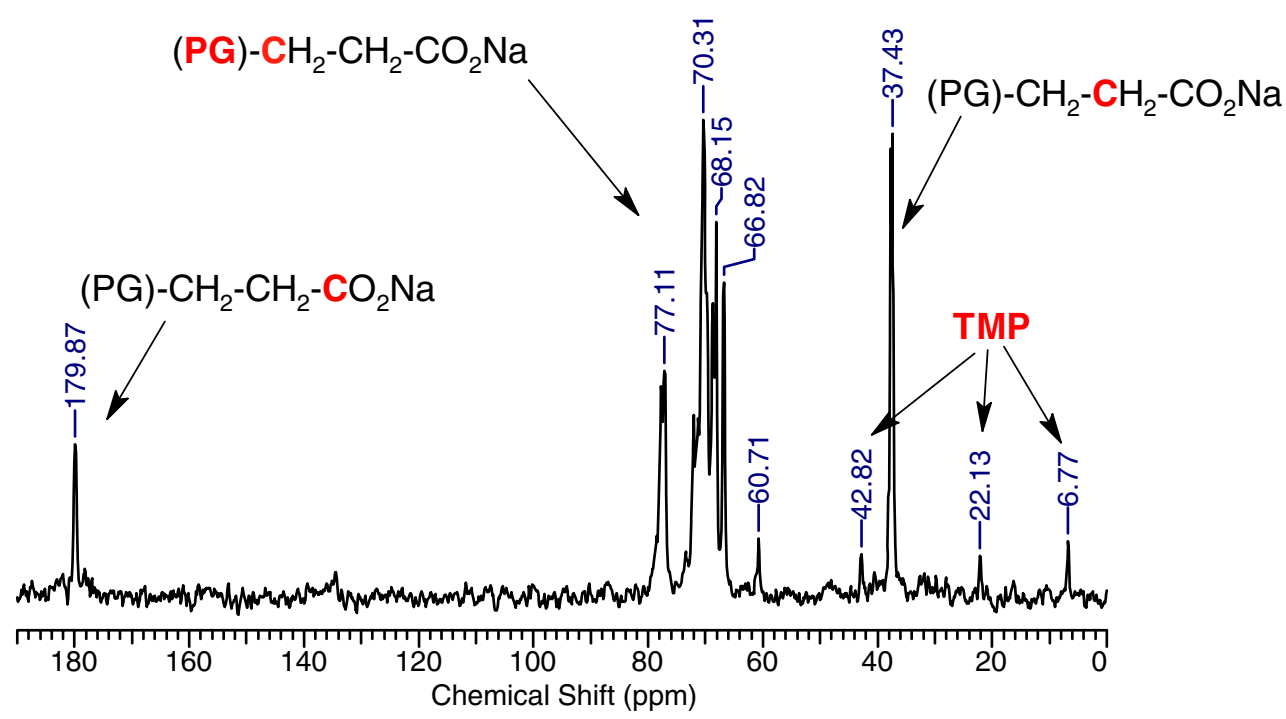


Table 1 Characterization data for the carboxylated hyperbranched polyglycerols (HBPG-cx)

\begin{tabular}{|c|c|c|c|c|c|}
\hline \multirow[t]{2}{*}{ Sample } & \multicolumn{2}{|l|}{ HBPG } & \multicolumn{2}{|l|}{ Carboxylated HBPG-cx } & \multirow[t]{2}{*}{$\%$ Modif. } \\
\hline & $\overline{\bar{M}_{\mathrm{n}}}$ & OH groups/polymer & $\mathrm{COO}^{-} \mathrm{Na}^{+}$groups/polymer & $\bar{M}_{\mathrm{n}}$ & \\
\hline 1 & 520 & 8.2 & 6.4 & 970 & $78 \%$ \\
\hline 2 & 1,030 & 15.1 & 13.5 & 2,280 & $89.4 \%$ \\
\hline 3 & 2,880 & 40.1 & 22.5 & 4,140 & $56.1 \%$ \\
\hline 4 & 6,480 & 89.7 & 55 & 10,220 & $62 \%$ \\
\hline
\end{tabular}

The values have been obtained from ${ }^{1} \mathrm{H}$ NMR spectra; $M_{n}$ values in $\mathrm{g}$ mol ${ }^{-1}$

Structures in solution and after surface deposition

The solution properties of the hyperbranched polyelectrolytes have been studied by dynamic light scattering (DLS) in aqueous solution and by AFM after deposition on a surface. All samples exhibit good solubility in aqueous solution at a wide range of $\mathrm{pH}$ values. With increasing molecular weight, the solubility in methanol decreases, which is a consequence of the multiple charges at the molecular termini.

The DLS results for sample 3 are summarized in Table 2 . At basic, neutral, and acidic $\mathrm{pH}$, the data always show two modes of distribution. It appears that in solution, unimolecular hyperbranched carboxylated polymers $\left(R_{\mathrm{h}}, 1\right)$ (unimers) coexist with large aggregates $\left(R_{\mathrm{h}}, 2\right)$. The values of $R_{\mathrm{h}}, 1$ have to be taken carefully, because they are near the resolution limit of DLS. It is only possible to conclude that these unimers do not show any strong dependence on concentration and $\mathrm{pH}$.

The second size distribution, $\left(R_{\mathrm{h}}, 2\right)$ aggregates, shows a clear dependence on $\mathrm{pH}$ and concentration. The carboxylic acid groups become more dissociated, as the $\mathrm{pH}$ decreases, which leads to a decrease of the size of the aggregates. Clearly, the charges promote aggregation, which is a consequence of an increasing amphiphilicity of the resulting structures. Concentration also influences the size of the aggregates, but this effect is not as strong as the influence of the $\mathrm{pH}$ value. Measurements at lower concentration (as low as $0.02 \mathrm{~g} / \mathrm{l}$ ) did not permit to observe the unimers' mode only. We conclude that aggregation is a dominant mechanism even at a low concentration. This is

Table 2 Dynamic light scattering data of the carboxylated hyperbranched polyglycerol sample $3 . R_{\mathrm{h}}, 1$ and $R_{\mathrm{h}}, 2$ : unimolecular and aggregates of the hyperbranched carboxylated polymers. $R_{\mathrm{h}}, 1$ and $R_{\mathrm{h}}, 2$ give the hydrodynamic radii of the respective modes

\begin{tabular}{lrcc}
\hline Concentration $\left(\mathrm{g} \mathrm{l}^{-1}\right)$ & $\mathrm{pH}$ & $R_{\mathrm{h}}, 1(\mathrm{~nm})$ & $\mathrm{R}_{\mathrm{h}}, 2(\mathrm{~nm})$ \\
\hline 2 & 10 & 1.8 & 168.9 \\
2 & 7 & 2.4 & 138.5 \\
2 & 2 & 1.1 & 98.2 \\
1 & 10 & 4.3 & 152.9 \\
1 & 7 & 9.3 & 105.6 \\
1 & 2 & 2.5 & 73.6 \\
\hline
\end{tabular}

most probably due to the presence of a rather apolar core in combination with the charged periphery of the macromolecules, resulting in core-shell amphiphilicity.

Tapping-mode AFM measurements for the samples 1 (Fig. 3) and 3 (Fig. 4) were performed after deposition on mica as a negatively charged substrate. The solutions were prepared at different $\mathrm{pH}$ in, all cases, at the concentration of $1 \mathrm{gl}^{-1}$ and spin-coated. Sample 1 (from a PG with $520 \mathrm{~g} \mathrm{~mol}^{-1}$ ) prepared under acidic conditions $(\mathrm{pH}=2)$ shows very small conglomerates of spherical particles $(2-3 \mathrm{~nm}$ in height), sometimes with beads-on-string morphology. This aggregation occurs already in solution, as the DLS results show. At $\mathrm{pH}$ 2, unimers are more collapsed (and form, therefore, higher structural features of 2-3 nm), presumably due to intramolecular hydrogen bonding. At neutral $\mathrm{pH}$, the AFM images show small structures (less than $1 \mathrm{~nm}$ in height) coexisting with large aggregates (10 $\mathrm{nm}$ in height). Unimers display extended conformation, as they are partially ionized (several Angstroms ( $\AA$ ) in height). Most interesting, at $\mathrm{pH} 10$, the formation of extended and highly ordered terrace structures of about $1.5 \mathrm{~nm}$ in height can be observed. Fragments of bilayers are also observed. Obviously, such terraces form upon evaporation of solvent for sample 1 . Similar structures do not exist at $\mathrm{pH}$ 7. This shows that for ordered aggregation, the macromolecules should be in the fully extended (open) conformation to minimize intramolecular interaction, which leads to a collapse of the unimers, and thereby, maximizes intermolecular interactions. All measurements were performed on a strongly charged substrate, and in the case of charged materials (at $\mathrm{pH} 10$ and partially at $\mathrm{pH}$ 7), adsorption is not favorable onto a surface with similar charges. This may explain why the surface is not fully covered with the first monolayer as the next monolayer already starts to be formed. The formation of rather flat mono- and bilayer structures is unprecedented for hyperbranched polymers. Similar images have been obtained for liquid crystalline dendrimers with perfectly branched structures [18]. This formation of ordered surface structures is most probably a consequence of the low polydispersity of the materials.

Sample 3 (from PG of 2,880 $\mathrm{g} \mathrm{mol}^{-1}$ ) forms aggregates upon adsorption at $\mathrm{pH} 2$ (diameter: $100-300 \mathrm{~nm}$, the height is about $3-5 \mathrm{~nm})$. These structures are arranged not regularly (particularly regarding their distance) as charged micelles. On the other hand, the pattern observed cannot be 

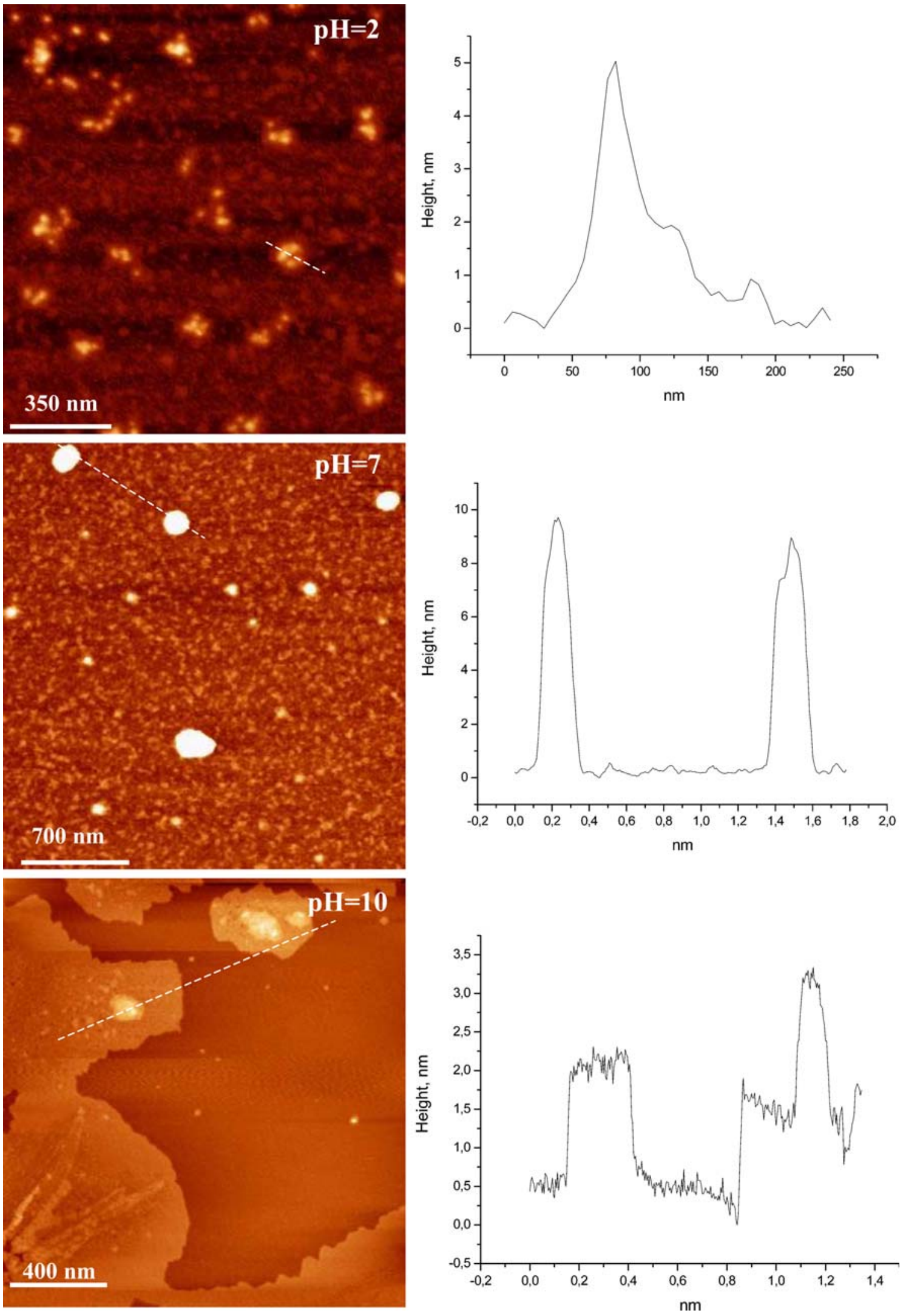

Fig. 3 AFM micrograph (left) with corresponding height profile (right) of sample 1 from an aqueous solution $\left(1 \mathrm{~g} 1^{-1}\right)$ at different $\mathrm{pH}(2,7$, and 10) on a mica substrate (tapping mode) 

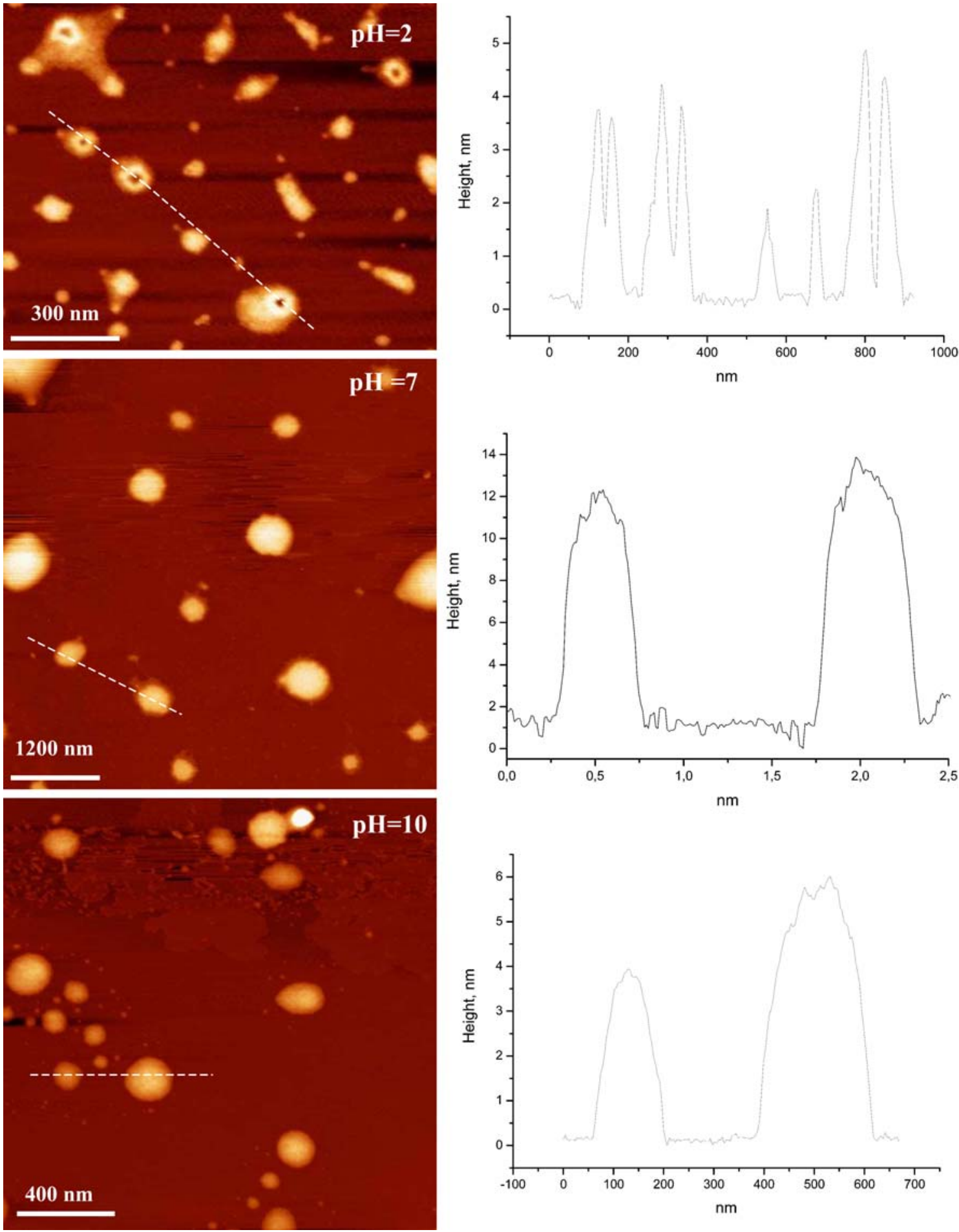

Fig. 4 AFM micrograph (left) with corresponding height profile (right) of sample 3 from an aqueous solution $\left(1 \mathrm{~g} 1^{-1}\right)$ at different $\mathrm{pH}(2,7$, and 10), deposited on mica substrate (tapping mode)

the result of coincidental adsorption. Also, this arrangement cannot be driven by charge repulsions, as the carboxylic acid groups are not ionized at $\mathrm{pH} 2$, nor because of excluded volume interaction, as the distance between them is too large (ordering can occur in the case of closely packed particles). Therefore, this material may either be molecularly dissolved in solution at $\mathrm{pH} 2$ or exist as loosely connected, swollen aggregates and initially 
adsorb onto the surface. As a consequence, it covers the surface more or less fully. Then, upon water evaporation, the material does not undergo only $Z$-collapse (in the vertical direction that leads to the dense layer) but also $X-Y$ (lateral) collapse (in a "dewetting" like process). Thus, the film forms islands, and their shrinkage occurs more or less with the same rate. In the case of the toroids, shrinkage may occur simultaneously from the center and from the periphery of the islands. This mechanism is not sufficient to form intermolecular aggregates in the case of lower molecular weight (sample 1). The formation of the ringlike, toroidal structures therefore may be envisaged as an interplay of segment mobility during the drying process, dewetting phenomena and remaining surface charge distribution, which constitutes a complex non-equilibrium process depending on preparation route and conditions.

At $\mathrm{pH} 7$, sample 3 forms larger aggregates (up to 15-nm high), which also appear to exist in solution. On the surface, these structures are not well-defined. They usually consist of a dense core and an extended, stabilized shell. In this case, these are low-density aggregates, the ratio diameter/height (500-nm large and $15-\mathrm{nm}$ high) is 33 , if assuming a near spherical geometry and merely $Z$-collapse upon drying. For the $Z$-collapse of dense micelles, the diameter/height ratio is usually considerably lower, for example, 3.33 for polystyrene-block-poly(2-vinylpyridine).

Under basic conditions, smaller aggregates are observed, but they are arranged in an unexpected manner: several particles of very different diameters are localized in close proximity, but are not connected to each other in most cases. Between such "populations" empty spaces are observed. This might reflect breaking of larger aggregates that existed in solution during the deposition onto several smaller ones.

\section{Conclusion}

The preparation of carboxylated hyperbranched polyglycerols was achieved by post-modification of the hydroxyl groups via Michael addition of acrylonitrile, followed by hydrolysis. High conversion (89\%) could only be achieved for low molecular weight starting materials (PG 520 and $1,030 \mathrm{~g} \mathrm{~mol}^{-1}$ ). Nevertheless, the modification based on Michael addition of acrylonitrile and subsequent hydrolysis afforded considerably higher degrees of modification than previously reported procedures [12]. The solution properties of the materials have been investigated by DLS. The results show the formation of large aggregates with the size depending on the $\mathrm{pH}$ value. After deposition on a negatively charged mica surface, the structures observed by AFM show the coexistence of aggregates and unimers. In the case of the lower molecular weight sample (PG $520 \mathrm{~g}$ $\mathrm{mol}^{-1}$ ), extended and highly ordered terrace structures were formed, which are unprecedented for hyperbranched polymers.

In a recent work, the materials have successfully been employed for the fabrication of composite organic-inorganic multilayer thin films, using electrostatic layer-bylayer self-assembly [19]. The consecutive, alternating deposition of multilayers led to linear growth behavior with increasing number of deposition steps.

\section{References}

1. Turner SR, Walter F, Voit BI, Mourey TH (1994) Macromolecules 27:1611

2. Gong A, Liu C, Chen Y, Zhang X, Chen C, Xi F (1999) Macromol Rapid Commun 20:492

3. van Duivenbode RC, Rajanayagam A, Koper GJM, Baars MWPL, de Waal BFM, Meijer EW (2000) Macromolecules 33:46

4. De Groot D, de Waal BFM, Reek JNH, Schenning, APHJ, Kamer PCJ, Meijer EW, van Leeuwen PWNM (2001) J Am Chem Soc 123:8453

5. Mori H, Seng DC, Lechner $H$, Zhang M, Müller AHE (2002) Macromolecules 35:9270
6. a) Dautzenberg H, Jaeger W, Kötz J, Philipp B, Seidel C, Stscherbina D, (1994) Polyelectrolytes - formation, characterization and application. Hanser, Munich b) Akari S, Schrepp W, Horn D (1996) Phys Chem 100:1014

7. Welch P, Muthukumar M (2001) Macromolecules 34:8286

8. Ramzi A, Scherrenberg R, Joosten J, Lemstra P, Mortensen K (2002) Macromolecules 35:827

9. Borisov OV, Daoud M (2001) Macromolecules 34:8286

10. Sunder A, Hanselmann R, Frey H, Mülhaupt R (1999) Macromolecules 32:4240

11. Kainthan RK, Janzen J, Levin E, Devine DV, Brooks DE (2006) Biomacromolecules 7:703

12. a) Schwab E, Mecking S (2005) J Polym Sc Polym Chem 43:4609 b) Türk H, Haag R, Alban S (2004) Bioconjug Chem 15:162
13. Buhleier E, Wehner W, Vögtle F (1978) Synthesis 155:8

14. Brabander-van den Berg EMM, Meijer EW (1993) Angew Chem Int Ed 32:1308

15. Wörner C, Mülhaupt R (1993) Angew Chem Int Ed 32:1306

16. van Hest JCM, Baars MWPL, Elissen Román C, van Genderen MHP, Meijer EW (1995) Macromolecules 28:6689

17. Stiriba SE, Kautz H, Frey H (2002) J Am Chem Soc 124:9698

18. Collaud Coen M, Lorenz K, Kressler J, Frey H, Mülhaupt R (1996) Macromolecules 29:8069

19. Kim DH, Lee OJ, Barriau E, Lee X, Caminade AM, Majoral JP, Frey H, Knoll WJ (2006) Nanosci Nanotechnol (in press) 